\title{
A Statistical Analysis on Environmental Factors Affecting Education Efficiency of China's 4-year Universities
}

\author{
Guanghong Zhang ${ }^{1, a}$, , Weonjae Kim ${ }^{1, b}$ \\ ${ }^{1}$ Department of International Trade, Incheon National University, Yeonsu-gu, Incheon, Korea \\ a cherryzhang1314@hotmail.com, ${ }^{\mathrm{b}}$ kwj5502@inu.ac.kr \\ * Guanghong Zhang
}

Keywords: Education efficiency, Data Envelopment Analysis (DEA), Environmental factors, Government's support policies

\begin{abstract}
This study deals with the statistical analysis for checking significance of environmental factors impacting on the education efficiency of the 80 universities in China. As a result of some previous studies and statistical consideration, we adopted a Data Envelopment Analysis (DEA) model to perform the relevant analysis and assumed that there exist 4 major environmental factors including government's support policies, density of university, economic development of the city, and city rating level. The results of statistical analysis reveal that both factors of the total number of universities in city and the city's class show the highly significant impacts on education efficiency of the China's universities, and also the factor of economic development of the city proves its proper statistical significance. However, the factor of government's support policies turns out little impact on education efficiency statistically. Judging from these results of case analysis, the Chinese government is recommended to redress its policies of financial support to universities. The detailed study results will be provided in the main paper.
\end{abstract}

\section{Introduction}

Higher education is one of the important components of the interconnected education system. The relative level of higher education is a sign of a country's comprehensive national strength, potential power for future and the level of economic and social development. Higher education usually includes various types of educational institutions with high-level learning and training, teaching, research, and social services as their main tasks and activities. The second half of the 20th century was an unusual expansion and qualitative change in the history of the development of higher education.

In China, the rapid increase in the demand for senior specialized talents and the urgent need for students to take higher education opportunities has made China's higher education develop rapidly. There are three levels of higher education in China: general higher education, adult higher education, and self-taught higher education examinations. For each level the National Unified Examination for Higher Education Enrollment, a nationwide unified examination for the enrollment of colleges and universities, is required. It occupies the most important position in China's education system. As of 2017, there were total 2,914 colleges and universities in China, an increase of 35 colleges and universities from 2016. This includes 2,631 general 4-year universities (including 265 independent colleges), an increase of 36 universities from last year (one independent college less than 2016) and 283 adult higher education colleges, one less than 2016. Therefore, according to China's current situation, it is more important to study the education efficiency of 4year universities than other levels of universities.

In order to improve the education efficiency of Chinese universities, it is necessary to find relevant influencing factors from both internal and external aspects. Internal factors are the factors that control and adjust influencing factors of education efficiency in each university. On the contrary, external factors are environmental factors, which cannot be self-adjusted by universities, but they are social economic development, policies, and other social factors that have an impact on 
education efficiency. Thus, the study of social and economic environmental factors is also necessary for the improvement of education efficiency.

This paper has two main purposes. One is to investigate the overall education efficiency of China's 4-year universities, and to understand the quality of education in major Chinese universities. The second is to analyze the impact of major environmental factors on the efficiency of education, and thus explore the efficiency improvement strategies for China’s 4-year universities.

\section{Theoretical Backgrounds}

A variety of methods have been used to evaluate the performance efficiency of universities. One of the analysis method called Data Envelopment Analysis (DEA) is a popular performance measurement tool widely used in non-profit field. In other words, DEA is one of the main techniques used in the public and private sectors to evaluate performance across a set of homogeneous production units with multiple resources and products [1]. It was proposed by Charnes, Cooper and Rhodes, based on concepts introduced by Farrell in 1957[2].

DEA Analysis Model has a wide application and has been applied to evaluate efficiency in many fields, such as finance, police force performance [3], resource allocation [4] or environmental efficiency [5]. DEA has also been applied to evaluate performance in basic education institutions, universities, academic programs and research centers.

DEA measures the relative efficiency of an institute and objectivity is the most important advantage provided. The approach of DEA has been used for higher education institutes in many countries such as Australia [6][7][8], China[9], Germany[10], United Kingdom[11][12] and USA[13].

As a non-profit making institution, a university produces multiple outputs (e.g. graduates and publications) using multiple inputs (e.g. lecturers and facilities). In this study, we determine the educational efficiency of a university by combining these multiple factors (both inputs and outputs). The appropriate method for the determination of these multiple inputs and outputs is the DEA method.

Therefore, our study, by applying the above advances of statistical inference in DEA models, measures the 4-year universities' efficiency of China which located in the major provinces and municipalities.

\section{Research Model}

\subsection{Inputs and outputs for efficiency analysis}

In general research, the model for testing efficiency has two approaches: teaching efficiency and research efficiency. From the perspective of the university's main purpose, this study considers students as the most important subject in terms of university education efficiency. Consequently, the teaching efficiency model was adopted primarily and research efficiency is applied supportively in testing educational efficiency.

The assumption in the teaching efficiency model is that universities employ academic staffs to educate enrolled students to produce graduates with a certain level of quality. Thus, teaching efficiency is referring to the teaching performance of universities in delivering knowledge to undergraduate and postgraduate students. The main teaching resources of a university can be divided into human resources and infrastructure resources, and both resources are indispensable. Among them, human resources may include the number of professors, the number of students at the university, and University Student-Teacher Ratio which measures the eligibility of universities. In this paper, the above three factors are used as inputs in the research model.

Second, the infrastructure resources can be divided into two aspects: the scale of the university campus and the available area of the library per student. The scale of the university's campus determines the size of talent cultivation, and the library is the most used and important facilities for students, which can affect students' learning quality and learning enthusiasm. Therefore, these two 
items are also used as inputs in the model.

Finally, some studies considered annual science and technology funding as an output based on the argument that it is a kind of the outcomes of research performance. This means that if the research performance of a university is better, more funds will be attracted. In contrast, in this study, annual science and technology funding was treated as a resource for education activities, thus it was considered as an input.

In some studies [9], the employment rate of graduates is used as an output of the efficiency analysis. However, the quality of employment is another important concept and criteria that is different from the employment rate. A high employment rate does not mean that the quality of employment is also high, and high-quality employment reflects the results of university teaching more accurately. The overall Employment Competitiveness Index of graduates is an important indicator of high quality employment. Another concept is the rate of advanced study after graduation (divided into local advanced study rate and overseas advanced study rate). A higher graduate's advanced study rate results in a greater the overall strength of the university, also the higher the social recognition of the university. To summarize, the outputs are the employment rate of graduates, the overall employment competitiveness index of graduates, and the students' local advanced study rate and overseas advanced study rate.

The total inputs and outputs mix for efficiency analysis is shown in Table1 blow.

Table 1 Total inputs and outputs mix for efficiency analysis

\begin{tabular}{|l|l|}
\hline \multicolumn{1}{|c|}{ Inputs } & \multicolumn{1}{c|}{ Outputs } \\
\hline X1: Number of Professors & Y1: Employment Rate \\
\hline X2: Number of Students & Y2: Graduates Employment Competitiveness Index \\
\hline X3: University Student-Teacher Ratio & Y3: Local Advanced Study Rate \\
\hline X4: Campus Scale & Y4: Overseas Advanced Study Rate \\
\hline X5: Library Area Per Student & \\
\hline X6: Annual Science and Technology Funding & \\
\hline
\end{tabular}

\subsection{Research model for environmental factors analysis}

Factors affecting efficiency can be divided into internal factors and external factors (ie, environmental factors). In China, public universities play a leading role in education development. Therefore, for China, external environmental factors such as the economy, society, and government policies are all parts that should be considered when improving education efficiency.

This paper proposed four environmental factors: urban economic development, total number of four-year universities in the city, government's support policy, and the city's class. And the following four hypotheses are proposed.

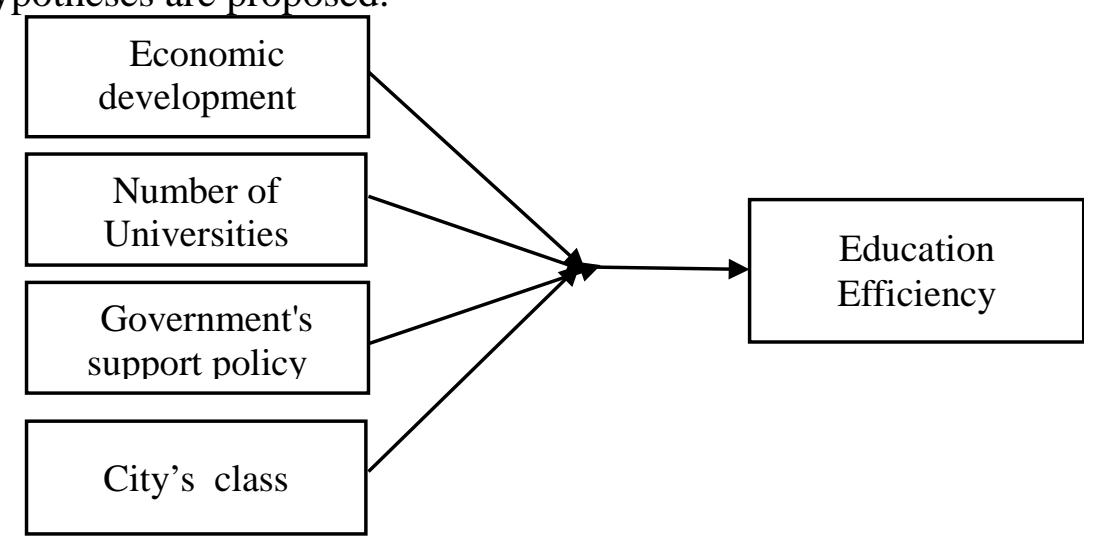

Figure 1 Research model for environmental factors analysis

H1: Government's support policy has a statistical significant influence on the education effectiveness of China's 4-year universities.

H2: Number of universities has a statistical significant influence on the education effectiveness of China's 4-year universities. 
H3: Economic development has a statistical significant influence on the education effectiveness of China's 4-year universities.

H4: City's class has a statistical significant influence on the education effectiveness of China's 4-year universities.

\section{Results}

\subsection{First step DEA results}

Based on the inputs and outputs presented in part 3.1 of this paper, we performed the DEA analysis for the first step. In this phase, we analyzed two efficiency estimates: original efficiency scores and bias-corrected scores. The results of the efficiency analysis are shown in Table 2 below.

Table 2 Comparison of two efficiency scores

\begin{tabular}{|c|c|c|c|c|}
\hline Efficiency Scores & Mean & Standard deviation & Min. & Max. \\
\hline Original & 0.86893 & 0.11172 & 0.65090 & 1 \\
\hline Bias-corrected & 0.80681 & 0.09453 & 0.61049 & 0.95471 \\
\hline
\end{tabular}

The mean value of the original efficiency scores was $0.86893(86.89 \%)$, the highest efficiency score was $1(100 \%)$ and the lowest efficiency score was $0.6509(65.09 \%) .22$ of the 80 universities(27.5\%) in our research data are $100 \%$ efficient, obtaining efficiency scores equalling 1. To eliminate the bias and improve the discrimination of DEA, we first estimated the bias and obtain a bias-corrected estimate. Bias-corrected efficiency scores showed a different result. The mean value was $0.80681(80.68 \%)$, the highest efficiency score was $0.95471(95.47 \%)$ and the lowest efficiency score was 0.61049(61.05\%). Therefore, the research results show that the education efficiency of China's 4-year universities is at a relatively high level (mean=0.81). However, there is still nearly $20 \%$ of the utilization of human and hardware facilities resources that need to be improved. Also, from the $34.44 \%$ (max-min=0.34422) gap between the highest and lowest efficiency scores, there was still a big gap in the education efficiency among the 80 four-year universities.

\subsection{Second step bootstrap multiple regression results}

At this stage, a Tobit Model was performed to examine the environmental determinant factors of education efficiency and to verify the four hypotheses proposed in part 3.2 of this paper. Figure 2 shows the result of the second step bootstrap regression.

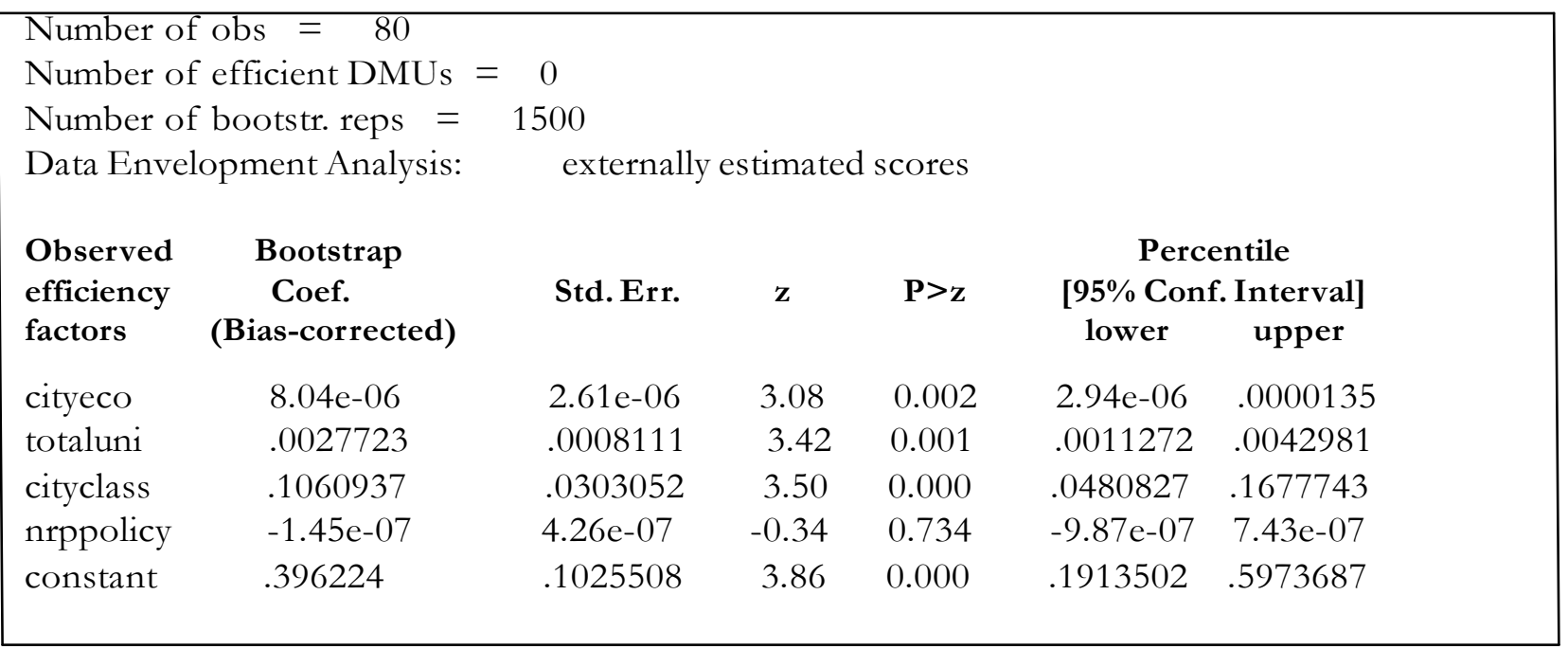

Figure 2 Bootstrap multiple regression results

As shown in Figure 2, the bootstrapped coefficients, standard errors, p-values and 95\% confidence intervals are reported. The p-values of the city's economic development, the total number of universities in the city and city's class were $0.002,0.001$ and 0.000 which had statistical significance. This result of statistical analysis revealed that both factors of the total number of 
universities in the city and the city's class showed substantial impacts on education efficiency of the China's universities, and also the factor of economic development of the city proved its proper statistical relevance. Therefore, the three hypotheses, H1, H2 and H4 have been statistically adopted. However, the p-value of government's support policy turned out to have almost no significant impact on education efficiency statistically (p-value: 0.734). Hence, the H3 hypothesis turned out to be unfounded.

\section{Discussion and Conclusion}

The paper has presented the DEA model which consists of 10 inputs and outputs to measure the education efficiencies of China's 4-year universities based on the teaching model. This was a new attempt for a study to utilize the DEA model to measure university performance. New measurement data such as University Student-Teacher Ratio and available library area per student were also introduced and analyzed as inputs. Despite considering more measures, the model has demonstrated a strong discriminatory power in differentiating between efficient and less efficient universities even with a small sample size of 80. In addition, future studies also can look into apply DEA model to assess university performance by focusing on a particular issue or different issues. For example, university's long and variable lead times between the inputs and outputs can be taken into consideration.

In the second stage, a bootstrap multiple regression analysis was performed to figure out that how many the environmental factors influenced the efficiency. The results of statistical analysis revealed that both factors of the total number of universities in the city and the city's class show highly significant impacts on education efficiency of the China's universities. It indicated that education is more efficient in cities with more universities. This is most likely because the more universities gathered, the easier it is to share information and resources, and the more diverse teaching or research exchanges between universities. These results can be very beneficial to the common improvement and growth of the university. For example, the government can consider trying to build an "online university group". This would assist university in more rural and less populated areas to overcome their isolate and be able to interact with other institutions. In addition to, the environmental factor, a city's class, shows that the more developed the city is, the more complete the urban infrastructure and the better the employment environment. Thus, it is more attractive to students. Also, the factor of economic development of the city upheld its proper statistical significance.

However, the government's support policy turned out to have no significant impact on education efficiency statistically (p-value: 0.734). Still, this was a question worth considering. Different universities in China receive different levels of economic support from the government every year. In particular, universities based mainly on science and engineering have received more support on average than liberal arts universities. However, the education efficiency of such universities was not generally considered to be more efficient than liberal arts universities. Therefore, for these universities, a new question emerged: how to use the government's economic support to increase education efficiency? On the other hand, it may be necessary for the government to consider adjusting the corresponding support policies based on the lack of education efficiency of their current policies.

Although our study supported most of the four hypotheses, it must be pointed out that the analysis of efficiency that was carried out has been limited to China's 4-year public universities, thus excluding private universities whose financing is completely different. Therefore, this paper was effective at measuring the university performance, but is not on absolute due to the limitation of the only analysing 80 public 4-year universities.

\section{References}

[1] Delimiro Visbal-Cadavid, Mónica Martínez-Gómez and Francisco Guijarro, Assessing the Efficiency of Public Universities through DEA. A Case Study. Sustainability 2017, 9(8), 1416. 
[2] Charnes, A., Cooper, W.W and Rhodes, E. (1978) Measuring the efficiency of DMUs, European Journal of Operational Research, 2, p. 429-444.

[3] Aristovnik, A.; Seljak, J.; Mencinger, J. Performance measurement of police forces at the local level: A non-parametric mathematical programming approach. Expert Syst. Appl. 2014, 41, 16471653.

[4] Fang, L.; Li, H. Centralized resource allocation based on the cost-revenue analysis. Comput. Ind. Eng. 2015, 85, 395-401.

[5] Lozano, S. A joint-inputs Network DEA approach to production and pollution-generating technologies. Expert Syst. Appl. 2015, 42, 7960-7968.

[6] Avkiran, N K (2001) 'Investigating technical and scale efficiencies of Australian universities through data envelopment analysis’ Socio-Economic Planning Sciences, 35(1) pp57-80.

[7] Madden, G, Savage, S \& Kemp, S (1997) 'Measuring public sector efficiency: a study of economics departments at Australian Universities’ Education Economics, pp153-167.

[8] Abbott, M \& Doucouliagos, C (2003) 'the efficiency of Australian universities: a data envelopment analysis’ Economics of Education Review, 22(1) pp89-97.

[9] Ng, Y C \& Li, S K (2000) 'measuring the research performance of Chinese higher education institutions: an application of data envelopment analysis’ Education Economics 8(2) pp139-156.

[10] Friedman, L \& Sinuany-Stern, Z (1997) 'Scaling units via the canonical correlation analysis in the data envelopment analysis context’ European Journal of Operational Research, 100 pp629-637.

[11] Athanassopoulos, A D \& Shale, E (1997) 'Assessing the comparative efficiency of higher education institutions in the UK by means of data envelopment analysis' Education Economics, 5 (2) pp117-134.

[12] Friedman, L \& Sinuany-Stern, Z (1997) 'Scaling units via the canonical correlation analysis in the data envelopment analysis context’ European Journal of Operational Research, 100 pp629-637.

[13] Coelli, T, Rao, D S P \& Battese, G E (1998) An Introduction to Efficiency and Productivity Analysis, Kluwer Academic, Norwell, MA. 